\title{
Healthcare utilization and costs among patients with non- functioning pituitary adenomas
}

\author{
Daniel J. Lobatto $\mathbb{D}^{1} \cdot$ Wilbert B. van den Hout ${ }^{2} \cdot$ Amir H. Zamanipoor Najafabadi $^{1} \cdot$ Anath N. V. Steffens $^{1}$. \\ Cornelie D. Andela ${ }^{3}$ - Alberto M. Pereira ${ }^{3}$. Wilco C. Peul ${ }^{1,4} \cdot$ Wouter R. van Furth ${ }^{1} \cdot$ Nienke R. Biermasz $^{3}$. \\ Thea P. M. Vliet Vlieland ${ }^{5}$
}

Received: 19 November 2018 / Accepted: 16 January 2019 / Published online: 22 March 2019

(c) The Author(s) 2019

\begin{abstract}
Purpose Non-functioning pituitary adenomas (NFPA) have a substantial impact on patients' health status, yet research on the extent of healthcare utilization and costs among these patients is scarce. The objective was to determine healthcare usage, associated costs, and their determinants among patients treated for an NFPA.

Methods In a cross-sectional study, 167 patients treated for an NFPA completed four validated questionnaires. Annual healthcare utilization and associated costs were assessed through the medical consumption questionnaire (MTA iMCQ). In addition, the Leiden Bother and Needs Questionnaire for pituitary patients (LBNQ-Pituitary), Short Form-36 (SF-36), and EuroQol (EQ-5D) were administered. Furthermore, age, sex, endocrine status, treatment, and duration of follow-up were extracted from the medical records. Associations were analyzed using logistic/linear regression.

Results Annual healthcare utilization included: consultation of an endocrinologist (95\% of patients), neurosurgeon (14\%), and/or ophthalmologist (58\%). Fourteen percent of patients had $\geq 1$ hospitalization(s) and $11 \% \geq 1$ emergency room visit(s). Mean overall annual healthcare costs were $€ 3040$ (SD 6498), highest expenditures included medication (31\%), inpatient care $(28 \%)$, and specialist care (17\%). Factors associated with higher healthcare utilization and costs were greater selfperceived disease bother and need for support, worse mental and physical health status, younger age, and living alone.

Conclusion Healthcare usage and costs among patients treated for an NFPA are substantial and were associated with selfperceived health status, disease bother, and healthcare needs rather than endocrine status, treatment, or duration of follow-up. These findings suggest that targeted interventions addressing disease bother and unmet needs in the chronic phase are needed.
\end{abstract}

Keywords Pituitary adenoma $\cdot$ NFPA $\cdot$ Healthcare utilization $\cdot$ Costs $\cdot$ Multidisciplinary $\cdot$ Value based healthcare

Supplementary information The online version of this article (https:// doi.org/10.1007/s12020-019-01847-7) contains supplementary material, which is available to authorized users.

Daniel J. Lobatto

d.j.lobatto@lumc.nl

1 Department of Neurosurgery, Leiden University Medical Center, Leiden, The Netherlands

2 Department of Medicine, Division of Endocrinology and Center for Endocrine Tumors, Leiden University Medical Center, Leiden, The Netherlands

\section{Introduction}

Patients with pituitary adenomas report impairments in health-related-quality of life (HRQoL) and a high disease burden [1-4]. In many cases, patients require lifelong (medical) treatment and monitoring by a multidisciplinary care team. Therefore, it is conceivable that total treatment costs are high, particularly in patients with endocrine

3 Medical Decision Making, Department of Biomedical Data Sciences, Leiden University Medical Center, Leiden, The Netherlands

4 Department of Neurosurgery, Medical Center Haaglanden, The Hague, The Netherlands

5 Department of Orthopaedics, Rehabilitation Medicine and Physical Therapy, Leiden University Medical Center, Leiden, The Netherlands 
deficits. Knowledge of the long-term healthcare utilization as well as the accompanying costs in patients with pituitary adenomas, however, is scarce.

NFPAs are highly prevalent among all pituitary adenomas [5] and can be considered as a separate entity, presenting with specific symptoms related to mass effects instead of hormonal excess. Studies describing healthcare utilization and/or costs of patients with pituitary adenomas, however, have focused primarily on functioning adenomas (i.e., Cushing's disease, acromegaly, prolactinoma) [6-12]. The only study presenting data on healthcare use among patients with an NFPA lacked physician-specific information (e.g., specialties visited, number of visits), as well as factors associated with increased healthcare utilization or costs. The study did confirm higher healthcare utilization and costs compared to a reference population of people without a pituitary disease [11].

The current study aims to determine healthcare usage, associated costs and their determinants among patients treated for an NFPA. It was hypothesized that in patients with an NFPA hypopituitarism, postoperative radiotherapy, and/or shorter duration of follow-up were associated with higher healthcare utilization and costs. We anticipated an association between a higher disease burden and needs for support and higher healthcare utilization and costs. It is expected that the identification of these disease- or care-related determinants for healthcare utilization and costs will be helpful for the further understanding and improvement of healthcare utilization/cost drivers, as well as improve value for the patient by making care more efficient, and improve outcomes.

\section{Patients and methods}

\section{Study design}

We performed a cross-sectional study in the Leiden cohort consisting of patients treated for an NFPA. The Leiden University Medical Center (LUMC) is a tertiary referral center in the Netherlands for the treatment of pituitary adenomas. The study was approved by the ethical committee of the Leiden University Medical Center prior to the study (p12.067). This study was part of a larger project, also assessing work-related disability [13].

\section{Patients}

All patients with an NFPA, aged $\geq 18$ years, and currently under active follow-up, were identified from the hospital registries and invited by their treating physician by means of a letter to participate. Exclusion criteria were follow-up of $<6$ months, insufficient Dutch language skills, incapacity to fill out the questionnaires, and living abroad. Recruitment took place between September 2016 and March 2017. In case of no response, participants were re-approached once through a letter. Written consent was obtained from each participant after full explanation of the purpose and nature of the study.

\section{Assessments}

The assessment consisted of a set of four validated questionnaires concerning healthcare usage and costs (Medical Consumption Questionnaire (iMTA MCQ)), perceived bother of disease and needs for support (Leiden Bother and Needs Questionnaire for pituitary patients (LBNQ-P)), HRQoL (Short Form-36 (SF-36), utility (EuroQol (EQ-5D)) and could be completed either digitally or on paper. In addition, sociodemographic and clinical data were collected from self-reports and medical records.

\section{Sociodemographic characteristics}

The following disease-specific and sociodemographic characteristics were collected from the medical records: age, sex, date of diagnosis, and treatment. Self-reported characteristics were: marital status, educational level, employment status, and endocrine status. Level of education was categorized into low, intermediate or high, based on the guidelines of Statistics Netherlands (CBS) [14], which corresponds with UNESCO's International Standard Classification of Education: Fields of Training and Education 2013 [15]. Employment status was categorized into three categories: (1) paid job, (2) no paid job, (3) retired. Treatment was divided into three categories: (1) wait-and-scan, (2) surgically treated patients, and (3) postoperative radiotherapy. Endocrine status was categorized as hypopituitarism ( $\geq 1$ endocrine $\operatorname{deficit}(\mathrm{s})$ ) or no deficits, according to hormone replacement therapy based on self-reported medication usage.

\section{Healthcare utilization}

The iMTA MCQ assesses whether patients had an appointment with various healthcare professionals (HCPs) during the past 12 months and the frequency of appointments. For this study, those HCPs considered relevant for patients with a pituitary adenoma were included (e.g., endocrinologist, neurosurgeon, ophthalmologist, ENT-doctor, neurologist, radiation oncologist, cardiologist, internist). Patients were allowed to add additional HCPs through an open question (other). Furthermore, the questionnaire assesses home care (i.e., nursing care, (government-subsidized) household help, including frequency and duration), emergency care (i.e., ambulance rides, emergency room (ER) visits, including frequency), hospital admissions 
(including frequency and duration) and medication usage (including frequency and dosage). A binary specialist care utilization score was computed: specialist care utilization was defined as high or low according to the median total number of visits to medical specialists during the previous 12 months (high use: $\geq 4$ visits).

\section{Perceived bother and needs for support}

The LBNQ-Pituitary is a disease-specific questionnaire, which was developed based on focus group interviews with patients [16]. For this study, the LBNQ-Pituitary consisted of 26 items divided into five subscales: mood problems, negative illness perceptions, issues in sexual functioning, physical and cognitive complaints, and issues in social functioning, from which index scores can be calculated (range 0-100). A detailed description of how the items are scored has been previously published. Higher scores indicate greater bother by the consequences of the disease and higher needs for support [16].

\section{Health-Related-Quality of Life and utility}

The $S F-36$ is a 36 -item HRQoL questionnaire, which covers eight domains: physical function, physical role, bodily pain, general health, vitality, social function, emotional role, and mental health. These subscales range from 0 to 100 , from which the physical and mental component score can be calculated. Higher scores indicate better HRQoL [17].

The EQ-5D (5-level) is a utility questionnaire consisting of five domains: mobility, self-care, usual activities, pain/ discomfort, and anxiety/depression, from which utility (range 0 to 1 ) can be calculated (EQ-5D index). The EQ-5D also includes a visual analog scale (VAS), which records self-reported health status (range 0-100). Higher scores indicate a better perceived health status [18].

\section{Costs}

Cost prices were obtained according to the Dutch manual for costing research [19], and prices were based on reference prices for 2016. Relevant reference prices are presented in Supplementary Table 4. Conversion of costs can be made based on the purchasing power parity provided by the Organization for Economic Co-operation and Development (OECD), which was 0.816 per dollar in 2016 [https://data.oecd.org/conversion/purchasing-powerparities-ppp.htm, accessed on 2 November 2018].

\section{Statistics}

Data entry was performed through an online survey platform. All statistical analyses were performed with IBM
SPSS 23.0 software (IMB SPSS Inc., New York, USA). Continuous variables are presented as means and standard deviations (SD) or medians with interquartile ranges (IQR), analyzed through unpaired $t$-test or Mann-Whitney $U$, where applicable. Categorical variables were calculated as frequencies with percentages and comparisons were performed through Chi-square analyses and Fisher's exact test, where applicable.

Logistic regression analysis was used to determine the relationship between specialist care utilization (high/low) as a dependent factor and possible contributing factors (i.e., disease-specific characteristics, sociodemographic characteristics, HRQoL, cost-utility, disease bother, needs for support). Associations are expressed as odds ratios (ORs) with the $95 \%$ confidence intervals (CIs) and $p$-values. Linear regression was used to determine the relationship between overall healthcare costs and all possible factors, which were in accordance with those of the logistic regression analysis. Associations are expressed as regression coefficients (B) with corresponding 95\% confidence intervals and $p$-values.

To control for confounding, variables associated with both the determinant and the outcome and not in the causal pathway of the relationship of interest were used as covariates in the multivariate analyses [20]. All associations were corrected for age and gender, depending on the determinant also for treatment type. ANCOVA was performed for the analysis of the disease bother and needs for support, correcting for age and gender (Supplementary Table 5).

For all analyses, results were considered statistically significant if the $p$-value was smaller than 0.05 (two-sided). Missing data on the questionnaires were handled by complete case analysis due to the low amount of missings $(<5 \%)$.

\section{Results}

\section{Study population and patient characteristics}

A total of 317 patients with an NFPA were identified from the hospital registry. After exclusion of ineligible patients, letters were sent to 265 patients, ultimately enrolling 167 $(63 \%)$ patients for this study (Fig. 1).

In total, $93(56 \%)$ patients were male, the mean age was 66.8 (SD 12.1) years and the median time since diagnosis was 9 years (IQR 4.8-18.4). Most patients $(n=105,63 \%)$ had undergone surgical treatment, followed by postoperative radiotherapy $(40,24 \%)$, and only wait-and-scan approach $(22,13 \%)$. The majority of patients $(121,73 \%)$ had one or more endocrine deficits. Adrenal insufficiency was present in 77 patients (46\%), which was highest among 
Fig. 1 Flow chart of in-/exclusion of patients with an NFPA

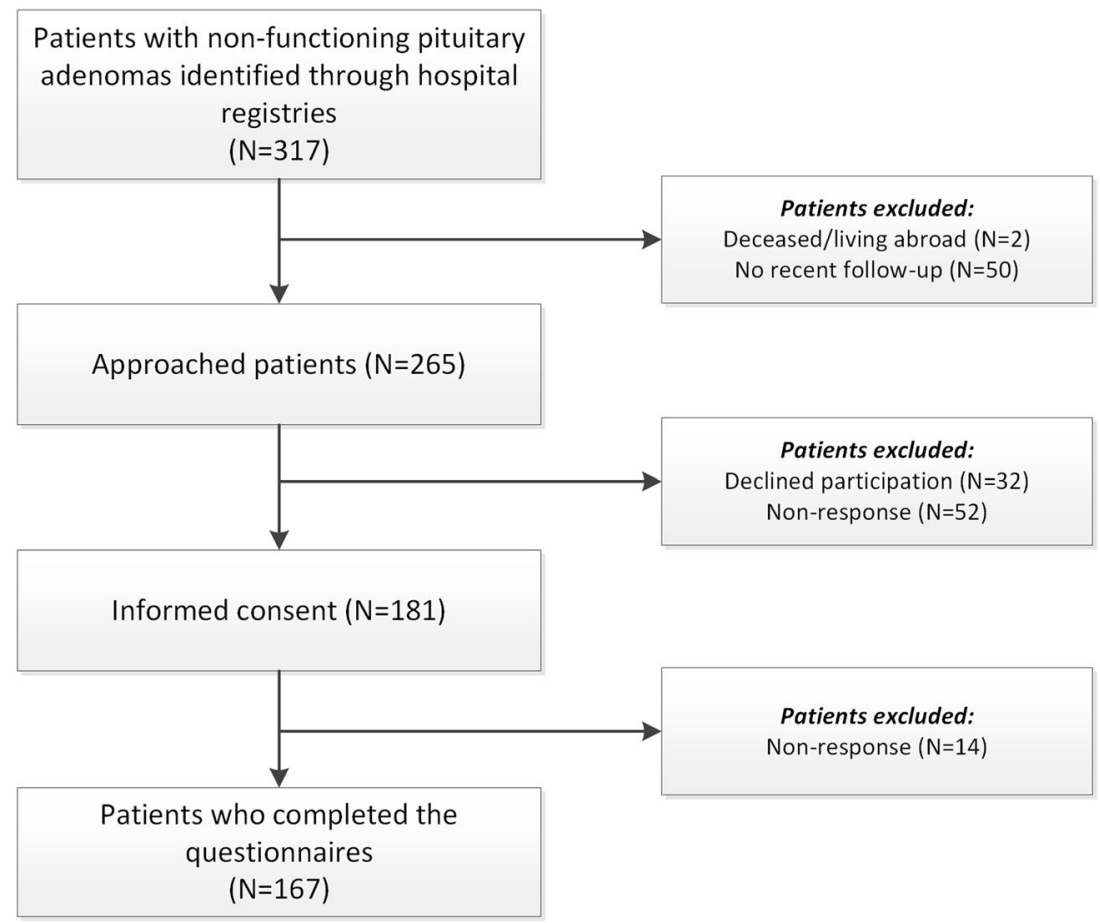

patients who had undergone postoperative radiotherapy (28, $68 \%)$, followed by surgical treatment $(43,41 \%)$ and waitand-scan $(6,27 \%)$ (Table 1).

\section{Healthcare utilization}

\section{Primary care}

The general practitioner was consulted in the previous year by 86 patients $(52 \%)$. Fifty-eight patients $(35 \%)$ had seen at least one other primary care health professional, most commonly the physiotherapist $(44,27 \%)$. There was no association between primary care utilization and patients with or without endocrine deficits, or duration of follow-up. Patients who had received postoperative radiotherapy had higher total physiotherapist and dietician visits (Tables 2 and 3).

\section{Specialist care}

Nearly all patients $(165,99 \%)$ had visited a medical specialist in the previous year, with a median of 2 (IQR $1-3$ ) specialists per year and a median of 3 visits (IQR 2-5) per year. The most commonly visited specialists were the endocrinologist (158 patients, 95\%), the ophthalmologist $(97,58 \%)$, and the neurosurgeon $(23,14 \%)$ (Tables 2 and 3).

\section{Hospital admissions and emergency care}

During the previous year, 23 patients (14\%) had been admitted to a hospital at least once (mean hospital stay: 6.8; range 1-99 days). Furthermore, ten patients (6\%) had at least one ambulance ride (mean 1.2; range 1-3 rides) and 19 patients $(11 \%)$ had visited the ER at least once during the previous year (mean 1.3; range 1-5 visits). There were no significant differences in the amount of ambulance rides, ER visits, nor in the number or duration of hospitalizations between patients with or without endocrine deficits, based on applied treatments or duration of follow-up (Tables 2 and 3).

\section{Determinants for healthcare utilization}

After correcting for relevant confounders, older patients (OR 0.973, 95\% CI 0.948;1.000), patients with longer time since diagnosis (OR 0.966, 95\% CI 0.933;1.000), as well as patients with a better mental and physical health status (SF36) (OR 0.929 , 95\% CI 0.896;0.962), and higher utility (EQ-5D) (OR 0.913, 95\% CI 0.870; 0.960) were significantly less likely to have high specialist care utilization. Contrarily, patients with higher overall perceived disease bother (OR 1.048, 95\% CI 1.020;1.076) and needs for support (LBNQ-Pituitary) (OR 1.033, 95\% CI 1.012;1.055) were significantly more likely to have high specialist care utilization. More specific, there was a significant need for support for issues regarding physical and cognitive 
Table 1 Characteristics of 167 patients diagnosed with and treated for an NFPA categorized by endocrine deficits

\begin{tabular}{|c|c|c|c|c|}
\hline & $\begin{array}{l}\text { Total } \\
(N=167)\end{array}$ & $\begin{array}{l}\text { No deficits } \\
(N=46)\end{array}$ & $\begin{array}{l}\text { Hypopituitarism } \\
(N=121)\end{array}$ & $p$-value \\
\hline \multicolumn{5}{|l|}{ Demographic characteristics } \\
\hline \multicolumn{5}{|l|}{$\operatorname{Sex}, N(\%)$} \\
\hline Female & $74(44.3)$ & $28(60.9)$ & $46(38.0)$ & 0.008 \\
\hline Age in years, mean (SD) & $66.8(12.1)$ & $66.9(11.2)$ & $66.8(12.5)$ & 0.963 \\
\hline \multicolumn{5}{|l|}{ Marital status, $N(\%)$} \\
\hline Relationship/married & $128(76.6)$ & $36(77.8)$ & $92(76.0)$ & 0.840 \\
\hline \multicolumn{5}{|l|}{ Education, $N(\%)$} \\
\hline Low & $71(42.5)$ & $21(45.7)$ & $50(41.3)$ & \\
\hline Intermediate & $41(24.6)$ & $10(21.7)$ & $31(25.6)$ & \\
\hline High & $55(32.9)$ & $15(32.6)$ & $40(33.1)$ & 0.838 \\
\hline \multicolumn{5}{|l|}{ Employment status, $N(\%)$} \\
\hline Paid job & $58(34.9)$ & $20(44.4)$ & $38(31.4)$ & \\
\hline No paid job & $25(15.1)$ & $4(8.9)$ & $21(17.4)$ & \\
\hline Retired & $84(50.3)$ & $22(46.7)$ & $62(51.2)$ & 0.229 \\
\hline \multicolumn{5}{|l|}{ Disease characteristics } \\
\hline $\begin{array}{l}\text { Time since diagnosis in years, median } \\
\text { (IQR) }\end{array}$ & $9.0(4.8-18.4)$ & $6.8(4.5-13.5)$ & $10.3(5.1-19.4)$ & 0.054 \\
\hline \multicolumn{5}{|l|}{ Treatment, $N(\%)$} \\
\hline Wait-and-scan & $22(13.2)$ & $13(28.3)$ & $9(7.4)$ & \\
\hline Surgery & $104(62.3)$ & $28(60.9)$ & $76(62.8)$ & \\
\hline Postoperative radiotherapy & $41(24.6)$ & $5(10.9)$ & $36(29.8)$ & $<0.001$ \\
\hline \multicolumn{5}{|l|}{ Current health status } \\
\hline EQ-5D score, mean $(S D)^{a}$ & $0.910(0.089)$ & $0.914(0.075)$ & $0.909(0.094)$ & 0.771 \\
\hline EQ-5D VAS, mean (SD) ${ }^{\mathrm{a}}$ & $73.6(20.5)$ & $74.8(21.8)$ & $73.2(20.1)$ & 0.660 \\
\hline SF-36 PCS, mean $(S D)^{a}$ & $44.5(10.6)$ & $44.6(10.0)$ & $44.4(10.8)$ & 0.899 \\
\hline SF-36 MCS, mean $(\mathrm{SD})^{\mathrm{a}}$ & $50.7(10.3)$ & $51.0(10.7)$ & $50.6(10.2)$ & 0.788 \\
\hline $\begin{array}{l}\text { LBNQ-Pituitary index score, mean } \\
(\mathrm{SD})^{\mathrm{b}}\end{array}$ & $13.4(15.9)$ & $11.5(15.6)$ & $14.0(16.0)$ & 0.397 \\
\hline
\end{tabular}

Due to rounding, not all percentages of the categorical variables add up to $100 \%$

$N F P A$ non-functioning pituitary adenoma, $N$ number, $S D$ standard deviation, IQR interquartile range, VAS visual analog scale, $E Q-5 D$ EuroQoL, $S F-36$ short form-36, $L B N Q$-Pituitary Leiden bother and needs questionnaire-pituitary, $M C S$ mental component scale, $P C S$ physical component scale

${ }^{a}$ Higher scores indicate better HRQoL

${ }^{\mathrm{b}}$ Lower scores indicate lower disease burden

Bold values indicates $p<0.05$ complaints, mood, negative illness perceptions and social functioning, but not for sexual functioning. There were no differences in specialist care utilization between patients with postoperative radiotherapy compared to other treatment regimens, as well as for those with and without hypopituitarism (Table 4).

\section{Costs}

The mean annual costs for patients with an NFPA were $€$ 3040 (SD 6498) (Table 3). The three largest expenditures were (pituitary-specific) medication ( $31 \%$ of overall costs) inpatient care (28\%), and specialist care (17\%) (Fig. 2). The overall costs did not significantly differ between patients with and without hypopituitarism, even though there were significantly higher costs for medication among those with hypopituitarism, postoperative radiotherapy, and longer duration of follow-up $(p<0.05)$ (Table 3).

\section{Determinants for increased costs}

Concerning healthcare costs, patients who were living alone had significantly higher healthcare costs (B 2960, 95\% CI $510 ; 5415)$ compared to those in a relationship. Patients with worse mental (B -107, 95\% CI -206;-9) or worse physical health status (SF-36) (B -178, 95\% CI -273;-82), lower utility (EQ-5D) (B -267, 95\% CI $-374 ;-161$ ), greater disease bother (B 123, 95\% CI 58;188), and a higher 


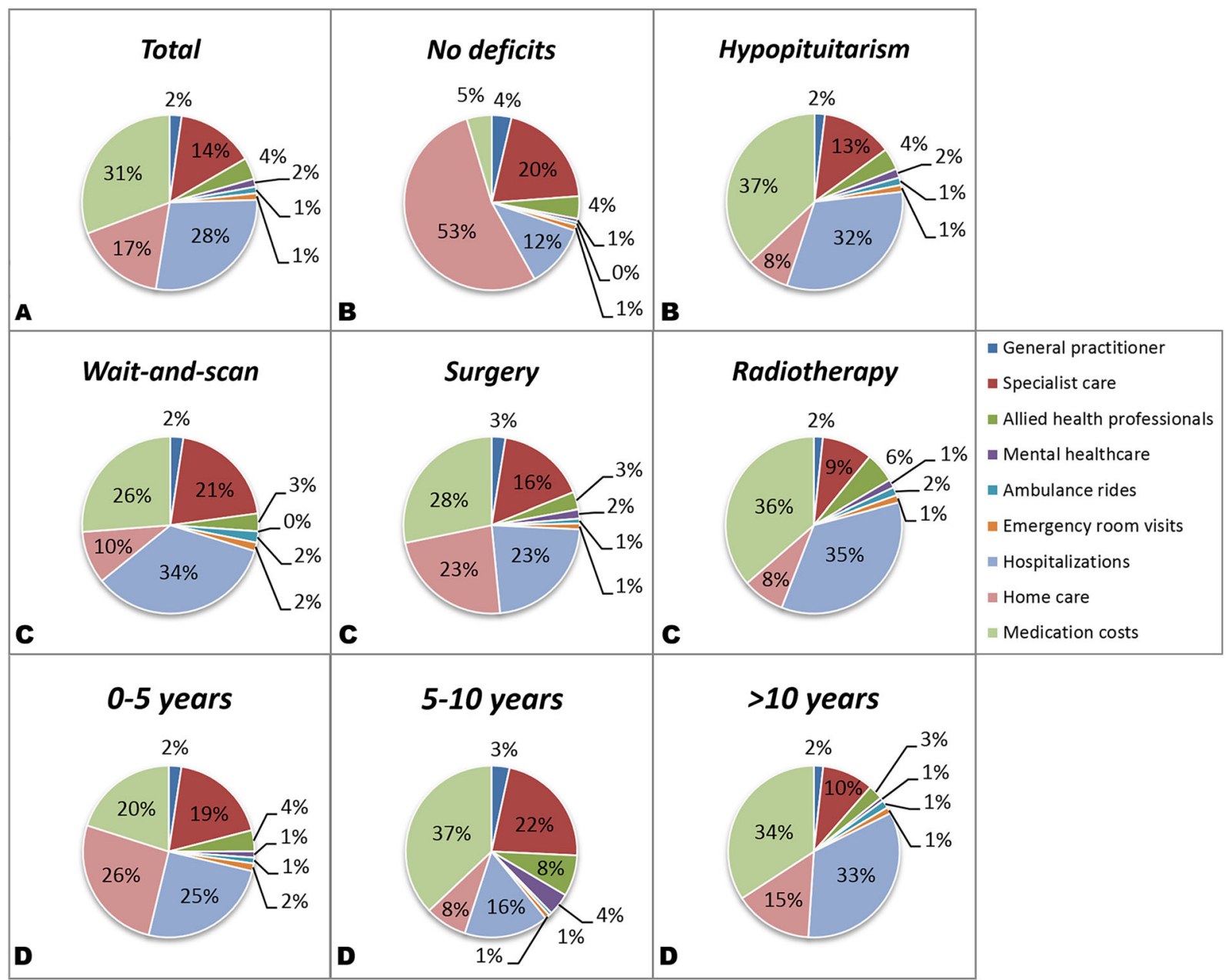

Fig. 2 Overall costs among all patients with an NFPA A, categorized per endocrine status $\mathbf{B}$, treatment algorithm $\mathbf{C}$ and duration of follow up $\mathbf{D}$

need for support (LBNQ-Pituitary) (B 130, 95\% CI 79;180) also had significantly higher costs, which was the case for all domains. Hypopituitarism, postoperative radiotherapy and duration of follow-up were not associated with higher costs (Table 4).

\section{Discussion}

The present study demonstrated that the overall healthcare utilization and costs in patients with an NFPA are substantial. Furthermore, this study shows that the endocrinologist and ophthalmologist are both actively involved in the care of over $50 \%$ of patients with an NFPA. In contrast to our hypothesis, overall healthcare utilization and overall costs did not differ between patients with or without endocrine deficits, or between the various treatments. Also, longer duration of follow-up was associated with lower healthcare utilization instead of higher utilization. These findings are intriguing, especially since it was anticipated that the burden of multiple hormone replacement therapy would have a significant impact on overall healthcare utilization.

Differences between patients appeared to be more related to subjective measurements such as HRQoL, disease bother and needs for support than objective outcomes or treatment variation. For instance, there was a strong association between lower HRQoL, higher self-perceived disease bother (on all domains of the LBNQ-pituitary) and needs for support (on all domains, except for sexual functioning) and increased healthcare utilization and costs. This makes patient-reported outcome measures (PROMS) a promising tool to gain better insight into the patient's condition and when to consider interventions to reduce healthcare utilization and costs and to optimize care trajectories. Further investigation towards optimal strategies supporting this hypothesis is necessary, perhaps through self-management interventions [21, 22].

Our study can be best compared to the study by Swearingen et al. [11], which is the only other currently 
Table 2 Average healthcare usage over the past 12 months in 167 patients with NFPA categorized by endocrine deficits

\begin{tabular}{|c|c|c|c|c|c|c|c|}
\hline \multirow[t]{2}{*}{ Healthcare service } & \multicolumn{2}{|l|}{$\begin{array}{l}\text { Total } \\
(N=167)\end{array}$} & \multicolumn{2}{|c|}{ No endocrine deficits $(N=46)$} & \multicolumn{2}{|c|}{$\begin{array}{l}\text { Hypopituitarism } \\
(N=121)\end{array}$} & \multirow[b]{2}{*}{$p$-value } \\
\hline & $\begin{array}{l}\text { Number of } \\
\text { patients, \% }\end{array}$ & $\begin{array}{l}\text { Visits } \\
\text { among } \\
\text { those } \\
\text { visiting, } \\
\text { mean }\end{array}$ & $\begin{array}{l}\text { Number of } \\
\text { patients, \% }\end{array}$ & $\begin{array}{l}\text { Visits } \\
\text { among } \\
\text { those } \\
\text { visiting, } \\
\text { mean }\end{array}$ & $\begin{array}{l}\text { Number of } \\
\text { patients, \% }\end{array}$ & $\begin{array}{l}\text { Visits } \\
\text { among } \\
\text { those } \\
\text { visiting, } \\
\text { mean }\end{array}$ & \\
\hline General practitioner & 51.5 & 4.1 & 50.0 & 4.8 & 52.1 & 3.9 & 0.101 \\
\hline \multicolumn{8}{|c|}{ NFPA related medical specialists } \\
\hline Endocrinologist & 94.6 & 2.1 & 89.1 & 1.8 & 96.7 & 2.2 & 0.685 \\
\hline Neurosurgeon & 13.9 & 1.7 & 19.6 & 1.1 & 11.7 & 2.1 & 0.084 \\
\hline Ophthalmologist & 58.4 & 2.1 & 65.2 & 2.4 & 55.8 & 2.0 & 0.311 \\
\hline ENT-doctor & 9.0 & 1.8 & 15.2 & 1.1 & 6.7 & 2.4 & 0.179 \\
\hline Neurologist & 9.6 & 2.2 & 8.7 & 2.0 & 10.0 & 2.3 & 0.885 \\
\hline Radiation oncologist & 1.8 & 1.3 & 2.2 & 1.0 & 1.7 & 1.5 & 0.642 \\
\hline Cardiologist & 10.2 & 1.8 & 10.9 & 1.2 & 9.9 & 2.0 & 0.907 \\
\hline Internist & 11.4 & 2.2 & 10.9 & 2.0 & 11.7 & 2.2 & 0.151 \\
\hline Others & 24.6 & 2.2 & 32.6 & 2.1 & 21.5 & 2.3 & 0.798 \\
\hline \multicolumn{8}{|c|}{ Total number of different specialists } \\
\hline 0 & 1.2 & - & 2.2 & - & 0.8 & - & \\
\hline 1 & 24.6 & 1.9 & 23.9 & 1.5 & 24.8 & 2.0 & \\
\hline 2 & 37.1 & 3.6 & 26.1 & 3.3 & 41.3 & 3.7 & \\
\hline 3 & 20.4 & 5.3 & 26.1 & 4.8 & 18.3 & 5.5 & \\
\hline 4 or more & 16.2 & 11.9 & 21.7 & 10.4 & 14.2 & 12.8 & 0.300 \\
\hline \multicolumn{8}{|l|}{ Occupational care } \\
\hline $\begin{array}{l}\text { Occupational } \\
\text { physician }\end{array}$ & 6.6 & 3.8 & 6.5 & 1.0 & 6.7 & 4.9 & 0.054 \\
\hline \multicolumn{8}{|l|}{ Mental healthcare } \\
\hline $\begin{array}{l}\text { Psychologist/ } \\
\text { psychiatrist }\end{array}$ & 8.4 & 8.2 & 4.3 & 5.0 & 10.0 & 8.8 & 0.764 \\
\hline \multicolumn{8}{|l|}{$\begin{array}{l}\text { Allied health } \\
\text { professionals }\end{array}$} \\
\hline Physiotherapist & 26.5 & 12.2 & 26.1 & 9.3 & 26.7 & 13.2 & 0.271 \\
\hline Speech therapist & 0.6 & 10.0 & - & - & 0.8 & 10.0 & 1.00 \\
\hline Dietician & 6.6 & 2.3 & 6.5 & 2.7 & 6.7 & 2.1 & 0.431 \\
\hline Occupational therapist & 0 & - & 0 & - & 0 & - & - \\
\hline \multicolumn{8}{|l|}{$\begin{array}{l}\text { Total number of different } \\
\text { allied health } \\
\text { professionals }\end{array}$} \\
\hline 0 & 64.7 & - & 69.6 & - & 63.3 & - & \\
\hline 1 & 29.9 & 9.2 & 23.9 & 6.1 & 32.5 & 10.1 & \\
\hline 2 & 4.2 & 17.4 & 4.3 & 14.0 & 4.2 & 18.8 & \\
\hline 3 & 0.6 & 28.0 & 2.2 & 28.0 & 0 & - & \\
\hline 4 & 0 & - & 0 & - & 0 & - & 0.244 \\
\hline \multicolumn{8}{|l|}{ Emergency care } \\
\hline $\begin{array}{l}\text { Ambulance rides, } N \\
(\%), \text { mean }\end{array}$ & 6.0 & 1.2 & 2.2 & 1.0 & 7.4 & 1.2 & 1.00 \\
\hline $\begin{array}{l}\text { Emergency room visit } \\
\text { (s), } N(\%) \text {, mean }\end{array}$ & 11.4 & 1.3 & 8.7 & 1.0 & 12.4 & 1.3 & 0.622 \\
\hline $\begin{array}{l}\text { Hospital admission(s) } \\
N(\%) \text {, duration }\end{array}$ & 13.8 & 6.8 & 13.0 & 4.0 & 14.0 & 16.2 & 0.222 \\
\hline \multicolumn{8}{|l|}{ Home care } \\
\hline $\begin{array}{l}\text { Community nurse, } N \\
(\%) \text {, hours }\end{array}$ & 1.2 & 122.5 & - & - & 1.7 & 122.5 & - \\
\hline $\begin{array}{l}\text { Informal care, } N(\%) \text {, } \\
\text { hours }\end{array}$ & 3.0 & 87.2 & 4.3 & 118.0 & 2.5 & 66.7 & 0.287 \\
\hline $\begin{array}{l}\text { Household help, } N \\
(\%) \text {, hours }\end{array}$ & 3.6 & 132.3 & 6.5 & 185.3 & 2.5 & 79.3 & 0.306 \\
\hline
\end{tabular}

$N F P A$ non-functioning pituitary adenoma, $N$ number, $S D$ standard deviation

$p$-value based on number and frequency of visits, (bold) $p<0.05$ 
Table 3 Medical and medication costs in euros $(€)$ over the past 12 months in 167 patients with an NFPA categorized by endocrine deficits

\begin{tabular}{|c|c|c|c|c|c|c|c|c|c|c|c|c|c|c|c|c|c|}
\hline \multirow{3}{*}{ Medical costs } & & \multicolumn{6}{|c|}{$\begin{array}{l}\text { Total } \\
(N=167)\end{array}$} & \multicolumn{6}{|c|}{$\begin{array}{l}\text { No endocrine deficits } \\
(N=46)\end{array}$} & \multicolumn{3}{|c|}{$\begin{array}{l}\text { Hypopituitarism } \\
(N=121)\end{array}$} & \multirow{3}{*}{ Overall $p$-value } \\
\hline & & \multicolumn{2}{|c|}{$\begin{array}{l}\text { Number of } \\
\text { patients }\end{array}$} & \multicolumn{4}{|c|}{$\begin{array}{l}\text { Costs among those } \\
\text { visiting }\end{array}$} & \multicolumn{2}{|c|}{$\begin{array}{l}\text { Number of } \\
\text { patients }\end{array}$} & \multicolumn{4}{|c|}{$\begin{array}{l}\text { Costs among those } \\
\text { visiting }\end{array}$} & $\begin{array}{l}\text { Number of } \\
\text { patients }\end{array}$ & \multicolumn{2}{|c|}{$\begin{array}{l}\text { Costs among those } \\
\text { visiting }\end{array}$} & \\
\hline & & $N$ & $\%$ & mear & & SD & & $N$ & $\%$ & mean & & SD & & $\%$ & mean & SD & \\
\hline \multicolumn{2}{|l|}{ General practiti } & 86 & 51.5 & & 5.67 & \multicolumn{2}{|c|}{131.28} & 23 & 50.0 & \multicolumn{2}{|c|}{159.00} & \multicolumn{2}{|c|}{156.99} & 52.1 & 126.97 & 120.68 & 0.498 \\
\hline \multicolumn{2}{|l|}{ Specialist care } & 165 & 98.8 & & 4.52 & \multicolumn{2}{|c|}{511.96} & 45 & 97.8 & \multicolumn{2}{|c|}{438.82} & \multicolumn{2}{|c|}{428.71} & 99.2 & 446.66 & 541.52 & 0.878 \\
\hline \multicolumn{2}{|c|}{ Allied health professionals ${ }^{\mathrm{a}}$} & 58 & 34.9 & & 8.21 & \multicolumn{2}{|c|}{378.54} & 14 & 30.4 & \multicolumn{2}{|c|}{289.93} & \multicolumn{2}{|c|}{245.31} & 36.7 & 366.75 & 412.67 & 0.339 \\
\hline \multicolumn{2}{|l|}{ Mental healthcare $^{b}$} & 14 & 8.4 & & 5.71 & \multicolumn{2}{|c|}{449.88} & 2 & 4.3 & \multicolumn{2}{|c|}{320.00} & \multicolumn{2}{|c|}{271.53} & 10.0 & 560.00 & 472.77 & 0.211 \\
\hline \multicolumn{2}{|l|}{ Ambulance rides } & 10 & 6.0 & & 8.00 & & 5.71 & 1 & 2.2 & 51. & .00 & - & - & 7.4 & 629.44 & 343.33 & 0.215 \\
\hline Emergency room vi & & 19 & 11.4 & & 7.16 & & 9.22 & 4 & 8.7 & & .00 & & 00 & 12.4 & 345.33 & 187.45 & 0.323 \\
\hline Hospitalization & & 23 & 13.8 & 618 & 8.00 & 107 & 7.13 & 6 & 13.0 & 190 & & 2624. & & 14.0 & 7700.00 & 12126.60 & 0.282 \\
\hline Home care ${ }^{c}$ & & 7 & 4.2 & 1209 & 4.57 & & 1.49 & 3 & 6.5 & 1746 & & 2058. & & 3.3 & 8068.50 & 3527.91 & 0.060 \\
\hline Total medical costs & & 167 & 100 & 210 & 3.43 & & 0.38 & 46 & 100 & 202 & & 4610. & & $121 \quad 100$ & 2131.95 & 7003.58 & 0.926 \\
\hline Medication costs & $\begin{array}{l}\text { Numl } \\
\text { patier }\end{array}$ & of & $\begin{array}{l}\text { Costs } \\
\text { using }\end{array}$ & amec & $\begin{array}{l}\text { ng th } \\
\text { licatio }\end{array}$ & & $\begin{array}{l}\text { Num } \\
\text { patie }\end{array}$ & er of & & $\begin{array}{l}\text { sts am } \\
\text { ing me }\end{array}$ & & & $\begin{array}{l}\text { Nun } \\
\text { patie }\end{array}$ & $\begin{array}{l}\text { mber of } \\
\text { ients }\end{array}$ & $\begin{array}{l}\text { Costs amc } \\
\text { using mec }\end{array}$ & $\begin{array}{l}\text { ig those } \\
\text { cation }\end{array}$ & alue \\
\hline & $N$ & $\%$ & Mean & & SD & & $N$ & $\%$ & $\mathrm{Me}$ & ean & SD & & $N$ & $\%$ & Mean & SD & \\
\hline Androgel & 56 & 33.5 & 445. & & 258 & 61 & 0 & - & - & - & & - & 56 & 46.3 & 445.88 & 258.61 & $<0.001$ \\
\hline Desmopressine & 11 & 6.6 & 99. & .12 & 66 & .92 & 0 & - & - & - & & - & 11 & 9.0 & 99.12 & 66.92 & 0.079 \\
\hline Thyrax & 90 & 53.9 & 34. & .29 & 12 & .94 & 0 & - & - & - & & - & 90 & 74.4 & 34.29 & 12.94 & $<0.001$ \\
\hline Genotropin & 30 & 18.0 & 2917. & & 1505 & 46 & 0 & - & - & - & & - & 30 & 24.8 & 2917.47 & 1505.46 & 0.001 \\
\hline Cabergoline & 3 & 1.8 & 1887. & & 2227 & .07 & 1 & 2.2 & & 23.92 & & - & 2 & 1.7 & 619.60 & 520.66 & 0.158 \\
\hline Quinagolide & 2 & 1.2 & 1056. & & 1405 & .73 & 1 & 2.2 & & 62.00 & & - & 1 & 0.8 & 2050.00 & - & 0.572 \\
\hline Hydrocortison & 77 & 46.1 & 411. & & 218 & .94 & 0 & - & - & - & & - & 77 & 63.6 & 411.82 & 218.94 & $<0.001$ \\
\hline Anticonceptives & 4 & 2.4 & 43. & .41 & 31 & .03 & 2 & 4.3 & & 27.90 & & - & 2 & 1.7 & 58.93 & 43.88 & 0.861 \\
\hline Total drug costs & 125 & 74.9 & 1250. & & 1610 & .18 & 4 & 8.7 & & 35.43 & 21 & 2.39 & 121 & 100 & 1254.44 & 1599.53 & $<0.001$ \\
\hline Overall costs & 167 & 100 & 3039. & & 6498 & 22 & 46 & 100 & & 27.15 & 46 & 2.22 & 121 & 100 & 3386.39 & 7065.90 & 0.265 \\
\hline
\end{tabular}

Reference prices are presented in Supplementary Table 4

$N F P A$ non-functioning pituitary adenoma, $N$ number, $I Q R$ interquartile range

${ }^{a}$ Physiotherapists, Speech therapists, Dieticians, Occupational therapists

${ }^{\mathrm{b}}$ Psychiatrists, psychologists

${ }^{c}$ Community nurse, informal care, household help

Bold values indicates $p<0.05$

available study reporting on healthcare utilization among 3792 patients with an NFPA. Comparable results were found for hospitalizations and office visits, however they found a higher number of ER visits (24\% vs. 11\%). This study, however, presented aggregated data from insurance claims databases, limiting comprehensive insight into which healthcare providers are consulted, lacked information on treatment and endocrine status and did not look at determinants for healthcare utilization and costs.

Other studies among patients with a functioning pituitary adenoma have mostly shown higher rates of hospitalizations (range 9-38.4\% vs. 14\%), comparable rates of proportion of patients visiting specialists (range 94-99\% vs. 99\%), and also higher ER visits (23-34\% vs. 11\%) [6-12]. The major differences in disease characteristics, however, limit comparability.
Concerning the costs of patients treated for an NFPA, the mean total costs found in our study were approximately fourfold lower compared to those reported by Swearingen et al. [11] ( $\$ 13,708$ vs. $€ 3039)$, which can be explained, at least in part, by the higher healthcare costs in the USA [23], but also show the variation between costs for patients with different types of pituitary adenomas. The most notable difference is the mean costs for medication, which is nearly ten times as high among the study by Swearingen et al. $(\$ 11,181$ vs. $€ 1250$ ). With regard to functioning adenomas, the mean total costs among patients with Cushing's disease ranged between \$ 26,269 and \$ 34,992; for acromegaly between $€$ 9200 and \$ 32,807 [6-12]. Both are considerably higher compared to the costs found in our study.

Pertaining to determinants, to the best of our knowledge, no other study has described determinants for healthcare utilization or costs of care for patients with an NFPA. One other 
Table 4 Logistic/linear regression analysis per determinant for medical specialist utilization and costs among patients with an NFPA

\begin{tabular}{|c|c|c|c|c|c|c|}
\hline \multirow[t]{2}{*}{ Determinant } & \multicolumn{3}{|c|}{$\begin{array}{l}\text { High specialist utilization } \\
\text { (adjusted for demographics) }\end{array}$} & \multicolumn{3}{|c|}{$\begin{array}{l}\text { Healthcare costs } \\
\text { (adjusted for demographics) }\end{array}$} \\
\hline & OR & $95 \% \mathrm{CI}$ & $p$-value & $B$ & $95 \% \mathrm{CI}$ & $p$-value \\
\hline \multicolumn{7}{|l|}{ Sociodemographic } \\
\hline Sex (ref: male gender) ${ }^{\mathrm{a}}$ & 1.504 & $0.804 ; 2.814$ & 0.202 & 1606 & $-404 ; 3617$ & 0.117 \\
\hline $\begin{array}{l}\text { Age }^{\mathrm{b}} \\
\text { Marital status (ref: relationship/ma }\end{array}$ & 0.973 & $0.948 ; 1.000$ & 0.047 & 51 & $-32 ; 133$ & 0.226 \\
\hline $\begin{array}{l}\text { Single/divorced/widow } \\
\text { Education (ref: high) }{ }^{\mathrm{a}, \mathrm{b}}\end{array}$ & 2.195 & $0.982 ; 4.905$ & 0.055 & 2963 & $510 ; 5415$ & 0.018 \\
\hline Intermediate & 1.559 & $0.728 ; 3.337$ & 0.253 & 1666 & $-980 ; 4311$ & 0.216 \\
\hline $\begin{array}{l}\text { Low } \\
\text { Employment status (ref: paid job }\end{array}$ & 1.778 & $0.768 ; 4.116$ & 0.179 & 687 & $-1712 ; 3087$ & 0.572 \\
\hline No paid job & 0.580 & $0.206 ; 1.635$ & 0.303 & -941 & $-4235 ; 2354$ & 0.574 \\
\hline Retired & 0.608 & $0.221 ; 1.674$ & 0.336 & -1061 & $-4293 ; 2171$ & 0.518 \\
\hline \multicolumn{7}{|l|}{ Disease specific } \\
\hline $\begin{array}{l}\text { Time since diagnosis }{ }^{\mathrm{a}, \mathrm{b}} \\
\text { Treatment (ref: wait-and-scan) }{ }^{\mathrm{a}, \mathrm{b}}\end{array}$ & 0.966 & 0.933;1.000 & 0.047 & 91 & $-9 ; 191$ & 0.074 \\
\hline Surgery & 0.656 & $0.483 ; 3.179$ & 0.656 & 484 & $-2520 ; 3488$ & 0.751 \\
\hline $\begin{array}{l}\text { Postoperative radiotherapy } \\
\text { Endocrine status (ref: no deficits) }\end{array}$ & 0.644 & $0.442 ; 3.743$ & 0.644 & 1895 & $-1520 ; 5310$ & 0.275 \\
\hline Hypopituitarism & 0.734 & $0.414 ; 1.861$ & 0.734 & 1456 & $-945 ; 3857$ & 0.233 \\
\hline \multicolumn{7}{|c|}{$\begin{array}{l}\text { HRQoL, utility, disease bother and needs for support } \\
\text { SF-36 }\end{array}$} \\
\hline Mental component scale & 0.942 & $0.909 ; 0.976$ & 0.001 & -107 & $-206 ;-9$ & $\mathbf{0 . 0 3 3}$ \\
\hline $\begin{array}{l}\text { Physical component scale } \\
\text { EQ-5D }\end{array}$ & 0.929 & $0.896 ; 0.962$ & $<0.001$ & -178 & $-273 ;-82$ & $<0.001$ \\
\hline EQ index (rescaled to $0-100)$ & 0.913 & $0.870 ; 0.960$ & $<0.001$ & -267 & $-374 ;-161$ & $<0.001$ \\
\hline $\begin{array}{l}\text { EQ VAS (scale 0-100) } \\
\text { Disease bother (LBNQ-Pituitary) }\end{array}$ & 0.968 & $0.951 ; 0.986$ & 0.001 & -98 & $-146 ;-51$ & $<0.001$ \\
\hline Physical and cognitive complaints & 1.037 & $1.016 ; 1.059$ & $<0.001$ & 77 & $25 ; 130$ & 0.004 \\
\hline Mood & 1.036 & $1.015 ; 1.057$ & 0.001 & 60 & $7 ; 114$ & 0.028 \\
\hline Negative illness perceptions & 1.044 & 1.018;1.070 & 0.001 & 61 & $-5 ; 127$ & 0.070 \\
\hline Sexual functioning & 1.021 & $1.003 ; 1.038$ & 0.018 & 111 & $64 ; 159$ & $<0.001$ \\
\hline Social functioning & 1.030 & $1.004 ; 1.056$ & 0.021 & 146 & $86 ; 207$ & $<0.001$ \\
\hline $\begin{array}{l}\text { Total index score } \\
\text { Needs for support (LBNQ-Pituita }\end{array}$ & 1.048 & 1.020;1.076 & 0.001 & 123 & $58 ; 188$ & $<0.001$ \\
\hline Physical and cognitive complaints & 1.031 & $1.013 ; 1.049$ & 0.001 & 88 & $44 ; 131$ & $<0.001$ \\
\hline Mood & 1.026 & $1.010 ; 1.043$ & 0.001 & 80 & $38 ; 122$ & $<0.001$ \\
\hline Negative illness perceptions & 1.019 & $1.004 ; 1.035$ & 0.013 & 51 & $8 ; 95$ & 0.021 \\
\hline Sexual functioning & 1.013 & $0.998 ; 1.029$ & 0.096 & 131 & 90;172 & $<0.001$ \\
\hline Social functioning & 1.023 & $1.001 ; 1.044$ & 0.036 & 155 & $104 ; 206$ & $<0.001$ \\
\hline Total index score & 1.033 & $1.012 ; 1.055$ & 0.002 & 130 & $79 ; 180$ & $<0001$ \\
\hline
\end{tabular}

SF-36, EQ-5D: higher scores indicate better HRQoL or utility/LBNQ-Pituitary: lower scores indicate lower disease bother or needs for support Ref reference category, (bold) $p<0.05, O R$ odds ratio, $C I$ confidence interval, HRQoL Health-Related-Quality of Life, SF-36 Short Form-36, EQ$5 D$ EuroQoL, LBNQ-Pituitary Leiden Bother and Needs Questionnaire

${ }^{\mathrm{a}, \mathrm{b}, \mathrm{c}}$ Adjusted for age (1), gender (2), treatment (3) 
study among patients with acromegaly previously reported that younger age, female gender, and hypopituitarism were associated with higher healthcare costs, and that the presence of an increasing amount of comorbidities was associated with an increased risk for hospitalizations and ER visits [7]. These results could not be confirmed in our study.

A strength of our study was the high response rate $(63 \%)$. The use of self-reported information on healthcare services was another strength of our study. This has recently been reported as the most suitable method for the measurement of healthcare utilization [24], thereby supporting the results presented here. This, however, was also a limitation of our study; since questionnaires were based on self-reports, it is possible that patients had difficulty distinguishing between various medical terms, i.e., differentiating between radiologists and radiation oncologists. Another important limitation is that even though we acknowledge that comorbidities are an important factor for a patient's HRQoL [7, 25], we were unable to analyze the impact of comorbidities in our study. Furthermore, the decision to invite only those patients who had visited the outpatient clinic in the prior 2 years (based on the tertiary referral function of our center) may have introduced a selection bias. We anticipated that this would influence results in both a negative and a positive way, since not only patients with better health status are referred back to the center they were referred by, but also patients with worse health status who are unable to travel to our center. The single center setting in which this study took place is another limitation that restricts generalizability of this study. However, by providing mean visits per patient, comparisons between healthcare systems can be made. Finally, we only included pituitary-specific medication in the analysis of the medication costs, which underestimates total medication costs.

The high active involvement by the endocrinologist and ophthalmologist in the care of patients with an NFPA in combination with the association between subjective determinants for healthcare utilization and costs are potential targets for future interventions. A next step could be to define trajectories of care and match these with the health status and healthcare needs of specific subgroups of patients in order to generate patient-tailored care. This might ultimately improve HRQoL and could lead to cost reductions in the long haul, however, prospective studies are necessary to confirm this hypothesis.

\section{Conclusion}

Healthcare utilization and costs among patients with an NFPA are substantial. Intriguingly, the extent of healthcare utilization and costs is independent of endocrine status and treatment algorithm, and costs are independent of duration of follow-up. Instead, worse HRQoL and more bother by the negative consequences of the disease and needs for support were associated with higher healthcare utilization and costs and can potentially be used as a tool to differentiate healthcare usage and cost drivers.

Funding This study was performed with the financial support of an ASPIRE young investigator research grant (WI219567, Pfizer, New York, USA). Pfizer, however, had no involvement in the project; the views expressed in this paper are those of the authors only and are not attributable to Pfizer.

\section{Compliance with ethical standards}

Conflict of interest The authors declare that they have no conflict of interest.

Informed consent Informed consent was obtained from all individual participants included in the study.

Publisher's note: Springer Nature remains neutral with regard to jurisdictional claims in published maps and institutional affiliations.

Open Access This article is distributed under the terms of the Creative Commons Attribution 4.0 International License (http://crea tivecommons.org/licenses/by/4.0/), which permits use, duplication, adaptation, distribution, and reproduction in any medium or format, as long as you give appropriate credit to the original author(s) and the source, provide a link to the Creative Commons license, and indicate if changes were made.

\section{References}

1. C.D. Andela, M. Scharloo, A.M. Pereira et al. Quality of life (QoL) impairments in patients with a pituitary adenoma: a systematic review of QoL studies. Pituitary 18, 752-776 (2015)

2. C.D. Andela, D.J. Lobatto, A.M. Pereira et al. How nonfunctioning pituitary adenomas can affect health-related quality of life: a conceptual model and literature review. Pituitary 21, 208-216 (2018)

3. O.M. Dekkers, A.A. van der Klaauw, A.M. Pereira et al. Quality of life is decreased after treatment for nonfunctioning pituitary macroadenoma. J. Clin. Endocrinol. Metab. 91, 3364-3369 (2006)

4. A.A. van der Klaauw, M. Kars, N.R. Biermasz et al. Diseasespecific impairments in quality of life during long-term follow-up of patients with different pituitary adenomas. Clin. Endocrinol. (Oxf.). 69, 775-784 (2008)

5. N. Karavitaki, Prevalence and incidence of pituitary adenomas. Ann. Endocrinol. (Paris) 73, 79-80 (2012)

6. M.S. Broder, M.P. Neary, E. Chang, W.H. Ludlam, Incremental healthcare resource utilization and costs in US patients with Cushing's disease compared with diabetes mellitus and population controls. Pituitary 18, 796-802 (2015)

7. M.S. Broder, M.P. Neary, E. Chang et al. Treatments, complications, and healthcare utilization associated with acromegaly: a study in two large United States databases. Pituitary 17, 333-341 (2014)

8. M.S. Broder, M.P. Neary, E. Chang et al. Burden of illness, annual healthcare utilization, and costs associated with commercially insured patients with cushing disease in the United States. Endocr. Pract. 21, 77-86 (2015) 
9. G. Didoni, S. Grottol, V. Gasco et al. Cost-of-illness study in acromegalic patients in Italy. J. Endocrinol. Invest. 27, 1034-1039 (2004)

10. H. Placzek, Y. Xu, Y. Mu et al. Clinical and economic burden of commercially insured patients with acromegaly in the United States: A retrospective analysis. J. Manag Care Spec. Pharm. 21, 1106-1114 (2015)

11. B. Swearingen, N. Wu, S.Y. Chen et al. Health care resource use and costs among patients with cushing disease. Endocr. Pract. 17, 681-690 (2011)

12. E. Lesén, D. Granfeldt, A. Houchard et al. Comorbidities, treatment patterns and cost-of-illness of acromegaly in Sweden: a register-linkage population-based study. Eur. J. Endocrinol. 176, 203-212 (2017)

13. D.J. Lobatto, A.N.V. Steffens, A.H. Zamanipoor Najafabadi et al. Work disability and its determinants in patients with pituitary tumor-related disease. Pituitary 21, 593-604 (2018)

14. Standaard Onderwijsindeling. 2016-Editie 2017/'18, Centraal Bureau voor de Statistiek (Den Haag/Heerlen, The Netherlands, 2018)

15. UNESCO Institute for Statistics, International Standard Classification of Education, ISCED-F 2013 (UNESCO Institute for Statistics, Montreal, Canada, 2014)

16. C.D. Andela, M. Scharloo, S. Ramondt et al. The development and validation of the Leiden Bother and Needs Questionnaire for patients with pituitary disease: the LBNQ-Pituitary. Pituitary 19, 293-302 (2016)

17. J.E. Ware, C.D. Sherbourne, The MOS 36-ltem short-form health survey (SF-36). Med. Care 30, 473-483 (1992)
18. EuroQoL Group, EuroQol-a new facility for the measurement of health-related quality of life. Health Policy (New York) 16, 199-208 (1990)

19. L. Hakkaart-van Roijen, N. van der Linden, C. Bouwmans, et al. Richtlijn voor het uitvoeren van economische evaluaties in de gezondheidszorg (Zorginstituut Nederland, The Netherlands, 2016)

20. I. Shrier, R.W. Platt, Reducing bias through directed acyclic graphs. BMC Med. Res. Methodol. 8, 70 (2008)

21. M. Panagioti, G. Richardson, N. Small et al. Self-management support interventions to reduce health care utilisation without compromising outcomes: a systematic review and meta-analysis. BMC Health Serv. Res. 14, 356 (2014)

22. C.D. Andela, H. Repping-Wuts, N.M.M.L. Stikkelbroeck et al. Enhanced self-efficacy after a self-management programme in pituitary disease: a randomized controlled trial. Eur. J. Endocrinol. 177, 59-72 (2017)

23. I. Papanicolas, L.R. Woskie, A.K. Jha, Health care spending in the United States and other high-income countries. JAMA 319, 1024 (2018)

24. L.I. van Lier, J.E. Bosmans, H.P.J. van Hout et al. Consensusbased cross-European recommendations for the identification, measurement and valuation of costs in health economic evaluations: a European Delphi study. Eur. J. Heal. Econ. 19, 993-1008 (2017)

25. J. Xuan, L.J. Kirchdoerfer, J.G. Boyer, G.J. Norwood, Effects of comorbidity on health-related quality-of-life scores: an analysis of clinical trial data. Clin. Ther. 21, 383-403 (1999) 